\title{
Commentary (on Bhugra: Using film and literature for cultural competence training and Teaching through cinema)
}

Filmmaker and former British Film Institute director Alan Parker famously remarked that 'film needs theory like it needs a scratch on the negative' (Parker, 1986). Worse, then, that any university department of film studies must be the prospect of a horde of vested interest groups (including 'professionals') rushing to judgement on whatever's on at the local multiplex. Although filmmakers may enlist psychiatrists to advise them during preproduction on 'psychological issues' (whatever that term comes to mean), few will take heed of psychiatrists' reactions to their films. This does not mean we should ignore film as a major influence on our patients, on us, on films yet unmade, television and print media, and a wider society. This said, there are two caveats. First, as in both Bhugra's articles (Bhugra, 2003a,b, this issue), psychiatrists see films through their medical training and psychiatric experience. Film is fantasy, and filmmakers have the right to tell any story they choose. Sometimes it is less about the representation of a psychiatric syndrome and more about a metaphorical statement: Scorsese's Taxi Driver and Kubrick's Full Metal Jacket spring to mind. If clinicians can use these films to make points about psychosis, that is entirely up to us, but neither Scorsese nor Kubrick claimed to have portrayed the absolute reality of psychosis in these films. Second, all criticism is subjective: along with filmic fantasy comes pleasure, and those of us who prefer Film A to Film B will go to great lengths to justify our choice. Bhugra states his chosen films are 'personal favourites', and if anything, this should strengthen his case for their use in formal teaching: one of the best predictors of excellence in teaching is the enthusiasm of the teacher. In this spirit, let me declare some of my own subjectivity. When I began my psychiatric training in 1992, one of the first pieces I read in the Psychiatric Bulletin was a review of The Prince of Tides by Pitt (1992). It took 5 years for the Bulletin to publish another film article, despite regular pieces on psychiatry and the media. Since then there have been only a handful of film pieces in the Bulletin and I therefore warmly welcome these two articles. I believe they will be widely read by busy clinicians, and will provoke thought and discussion beyond these pages.

The use of film to impart cultural norms is highly appropriate. Leaving aside our narrow professional concerns, cinema provides lessons in history, geography, sociology, anthropology, philosophy and so on. At its most blatant, many countries (most recently New Zealand with relation to The Lord of the Rings trilogy) use their films to promote tourism. So, too, national identities and mythologies have found expression in their cinema. Bhugra is correct in identifying such learning as both overt and covert. For clinicians and students, who may feel that they are being bombarded with new information, literature and film provide ideal opportunities for passive or covert learning. For many years, exposure to the arts and humanities was a requisite part of the premedical years in the USA. Latterly, medical training has discarded not just this, but in many UK universities the premedical year itself. Medical students will need some encouragement to read novels, but many of Bhugra's suggestions could be adapted into local teaching programmes. Guided discussion of particular films could deal with the danger of using only film to explore cultural complexities, where caricature and (at times xenophobic) stereotypes prevail; pictures may paint those thousand words, but not all of them are true. A flexible seminar structure is ideal, and this would avoid potential absolutist statements or lists of 'approved' films that are 'good for you' to watch. The fundamental property of cinema is to bring its audience into the world it creates, and it is the analysis of different perspectives (from inside out $v$. from outside in, or aggressor v. victim) that opens the spectator to new insights. I will not attempt to criticise or complement his filmography: as soon as such lists are printed they date, but moves are already under way to bring similar lists of films to College members, regularly updated, on its website.

In the article on teaching psychiatry, some pitfalls of film teaching are presented. The principal concern is that students would see the films as more real than the reality they seek to represent. Practical clinical exposure to patients should overcome students' tendency to overgeneralise film lessons. The arts can never replace 'hands on' clinical experience. Each of the main characters in Play Misty for Me and Fatal Attraction demonstrates borderline traits, but students should not conclude that such patients will rise to a fervour of homicidal rage. Nor should they be overimpressed with the strong cinematic association between psychosis and violence. Only in the movies. Another pitfall is to remove a character artificially from the film: as in life, the social context defines both the personality and the behaviour. This is often the agenda of celebrity-fixated newspaper critics, but their critiques can be a useful way to initiate discussion. To avoid narrow interpretations, at least two clinicians should lead the discussions at seminars and film clubs. For many years the American Psychiatric Association has integrated film screenings and discussions within its annual meeting (http://www.psych.org/pnews/98-0403/media.html), and beginning in 2000, the College has followed and dipped its collective toe into the water. Members can suggest fiction and documentary films to 
screen, based on either personal or film club experience. No doubt these two articles will help stimulate and irri-

special tate members into discussing their choices.

articles

\section{References}

BHUGRA, D. (2003a) Teaching

PARKER, A. (1986) British Cinema:

psychiatry through cinema. Psychiatric A PersonalView.12 March 1986,Thames

Bulletin, 27, 429-430.

Television.

- (2003b) Using film and literature for

PITT B. (1992) The Prince of Tides (film

cultural competence training review). Psychiatric Bulletin, 16, 463.

Psychiatric Bulletin, 27, 427-428.

Peter Byrne Senior Lecturer in Social and Community Psychiatry, Department of

Psychiatry and Behavioural Sciences, Royal Free and University College London

Medical School, Holborn Union Building, Whittington Hospital, London N19 5NF,

e-mail: p.byrne@ucl.ac.uk 